\title{
ASSESSMENT OF WIND RESOURCE STATISTICS IN SAMARIA REGION
}

\author{
Sergei Kolesnik ${ }^{1}$, Moshe Sitbon ${ }^{1}$, Asher Yahalom ${ }^{1}$, Alon Kuperman ${ }^{1,2}$ \\ ${ }^{1}$ Ariel University of Samaria, Israel; ${ }^{2}$ Ben-Gurion University of the Negev, Israel \\ skolesnik@gmail.com, sitbon222@gmail.com, asya@ariel.ac.il, alonk@bgu.ac.il
}

\begin{abstract}
Statistical characteristics of the wind resource in Samaria region of Israel have been analyzed by processing 11 years of wind data provided by the Israeli Meteorological Service, recorded at $10 \mathrm{~m}$ height above the ground (circa $710 \mathrm{~m}$ above the sea level). The cumulative mean wind speed at measurement height was shown to be $4.53 \mathrm{~m} \cdot \mathrm{s}^{-1}$ with standard deviation of $2.32 \mathrm{~m} \cdot \mathrm{s}^{-1}$. Prevailing wind direction is shown to be characterized by cumulative mean azimuth of $226^{\circ}$ with standard deviation of $79.76^{\circ}$. Moreover, Weibull distribution parameters were calculated yearly, monthly and seasonally, demonstrating good match with histogram-based statistical representations. Shape parameter of Weibull distribution was shown to reside within narrow range of 1.93 to 2.15 , allowing to assume Rayleigh distribution thus simplifying future wind turbines energy yield calculations.
\end{abstract}

Keywords: wind statistics assessment, Weibull distribution, Rayleigh distribution.

\section{Introduction}

During the last decade, wind characteristics and wind power potential have been studied in many countries worldwide $[1 ; 2]$ demonstrating that in spite of the prolonging global economic crisis, the worldwide wind power ascent continues. The world's wind power capacity added $38.6 \mathrm{GW}$ in 2009 , growing by $32 \%$ per year and $38.1 \mathrm{GW}$ in 2010 (24\% per year growth), demonstrating $110 \%$ growth in three years, to extend total installations up to $197.0 \mathrm{GW}$. A huge part of this capacity was installed in China with $22.7 \%$ of the world wind energy yield (about third of the world year's additions) and USA - $20.4 \%$, while Germany, Spain and India installing cumulative capacity of $30.9 \%$ together [3].

Wind energy became a significant player in the world's energy market. Global market worth of wind turbine installations in 2009 was around 63 billion USD. About half a million people are now employed, corresponding to GWEC estimates, by the wind industry around the world [4]. Main markets of the wind energy are situated in Asia, North America and Europe, each of which adds more than $10 \mathrm{GW}$ capacity a year.

Considering the Israeli energy market, the lack of the nonrenewable local energy resources has also forced the state to devote various efforts to the 'green' energy research and development, primarily in the area of solar energy. Recently, wind energy drew attention of energy initiatives as well. Yet the wind power amount produced in Israel is diminutive comparing to the continuously growing global market; however the last steps undertaken by the state are destined to improve the situation.

Israel currently operates a single wind farm in Asanyia Hill in the Golan Heights, with total installed capacity of $6 \mathrm{MW}$ (consisting of ten $600 \mathrm{~kW}$ turbines), satisfying the consumption of about 5 thousand families. The wind farm operates around $97 \%$ of the time and yields revenue of $\sim 1$ million USD a year. Indeed, wind energy potential of Israel is restricted because of surplus of moderate- or poor-wind velocities' areas, and is limited to the areas with sufficiently constant wind, some of which are being opposed by green groups on landscape conservation grounds. Nevertheless, the state continues efforts for bringing into operation of two more wind farms with a $50 \mathrm{MW}$ capacity [5].

It is emphasized in the Israel Knesset document that an improved estimate, based on the wind turbines technological development, gives a value much more than $500 \mathrm{MW}$ of the Israeli potential wind energy capacity [6]. One of perspective areas for efficient wind technology development, considering its climatic characteristics, is Samaria region.

It is well known that energy yield of a wind turbine mainly depends on wind energy characteristics and turbine power curve $[7 ; 8]$. In this paper, statistical characteristics of the wind speed behavior in Ariel are derived and investigated, relying on data collected be meteorological station located in Ariel University campus. 


\section{Materials and methods}

Eleven years of meteorological data (2001-2011), acquired by Ariel Meteorological Station and supplied by the Israeli Meteorological Service were processed. Measurement samples were taken at 10 meter height above the ground $(710 \mathrm{~m}$ above sea level) and were available at 10 minutes intervals. The city of Ariel is located at $32^{\circ} 6^{\prime} 21.6^{\prime \prime} \mathrm{N}, 35^{\circ} 11^{\prime} 16.43^{\prime \prime} \mathrm{E}$, in the center of Israel (Fig. 1). Ariel Meteorological Station is located inside Ariel University campus at eastern part of the city (Fig. 2), residing at $700 \mathrm{~m}$ above sea level.

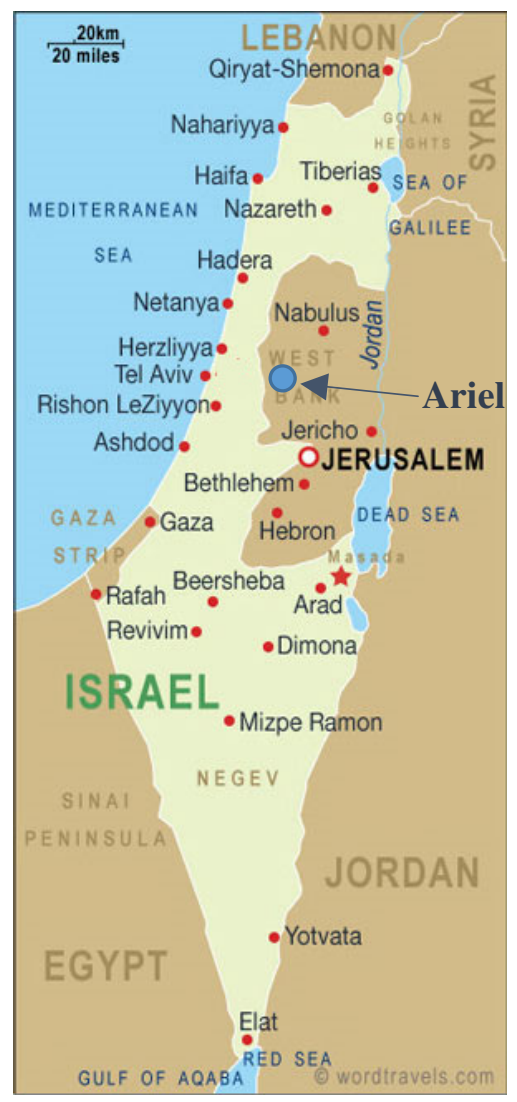

Fig. 1. Location of Ariel

The wind speed data was provided by meteorological station as raw matrix of wind speed and azimuth versus time at $10 \mathrm{~m}$ height, sampled at $10 \mathrm{~min}$. In reality, the sample time is much higher than stated and the available data sample is actually an average of tens to thousands of faster samples. An example of monthly wind speed raw data in Ariel represented by 10 min samples is shown in Fig. 3 . The raw vector is used to extract mean and standard deviation parameters and then can be either transformed into a histogram (discrete probability distribution function - PDF) or fitted to a known PDF, typically of Weibull type, as shown in Fig. 4. When creating a histogram, the bins are typically chosen to be $1 \mathrm{~m} \cdot \mathrm{s}^{-1}$ wide to match the resolution of the manufacturer provided turbine power curve data, resulting in the following discrete PDF,

$$
f_{H S T}(v)=f\left(v_{i}\right), \quad v_{i}-0.5 \leq v<v_{i}+0.5
$$

where $f\left(v_{i}\right)$ - the magnitude of the histogram bin, centered at $v_{i}$.

Weibull PDF is defined by two parameters: shape or Weibull modulus ( $k$, dimensionless), and scale $\left(c, \mathrm{~m} \cdot \mathrm{s}^{-1}\right.$ for wind speed). The general form of the Weibull PDF is given by

$$
f_{W B L}(v)=\frac{k}{c}\left(\frac{v}{c}\right)^{k-1} e^{-(v / c)^{k}}
$$

for positive wind speeds $(v>0)$ with parameters $c$ and $k$ related to the site wind speed mean $\mu_{v}$ and standard deviation $\sigma_{v}$ as [9] 


$$
\mu_{v}=c \Gamma\left(1+\frac{1}{k}\right)
$$

and

$$
\sigma_{v}=c \sqrt{\Gamma\left(1+\frac{2}{k}\right)-\Gamma^{2}\left(1+\frac{1}{k}\right)}
$$

respectively, where

$$
\Gamma(x)=\int_{0}^{\infty} t^{x-1} e^{-t} d t
$$

is the complete Gamma function. In case the wind raw data of a site is unavailable, but the mean and standard deviation of the wind speed are given, Weibull PDF is usually assumed and its parameters are extracted from (4) and (5). In general, several ways to extract Weibull parameters from raw data exist [10]. MATLAB function wblfit was used in this work.

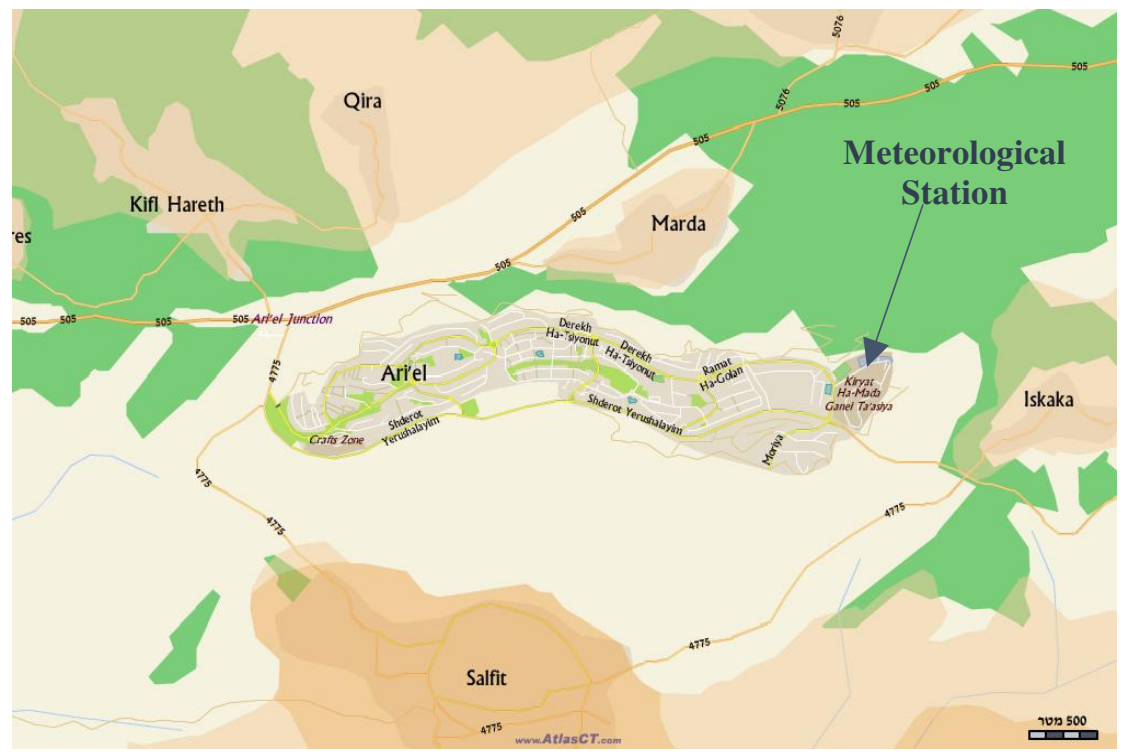

Fig. 2. Meteorological station location

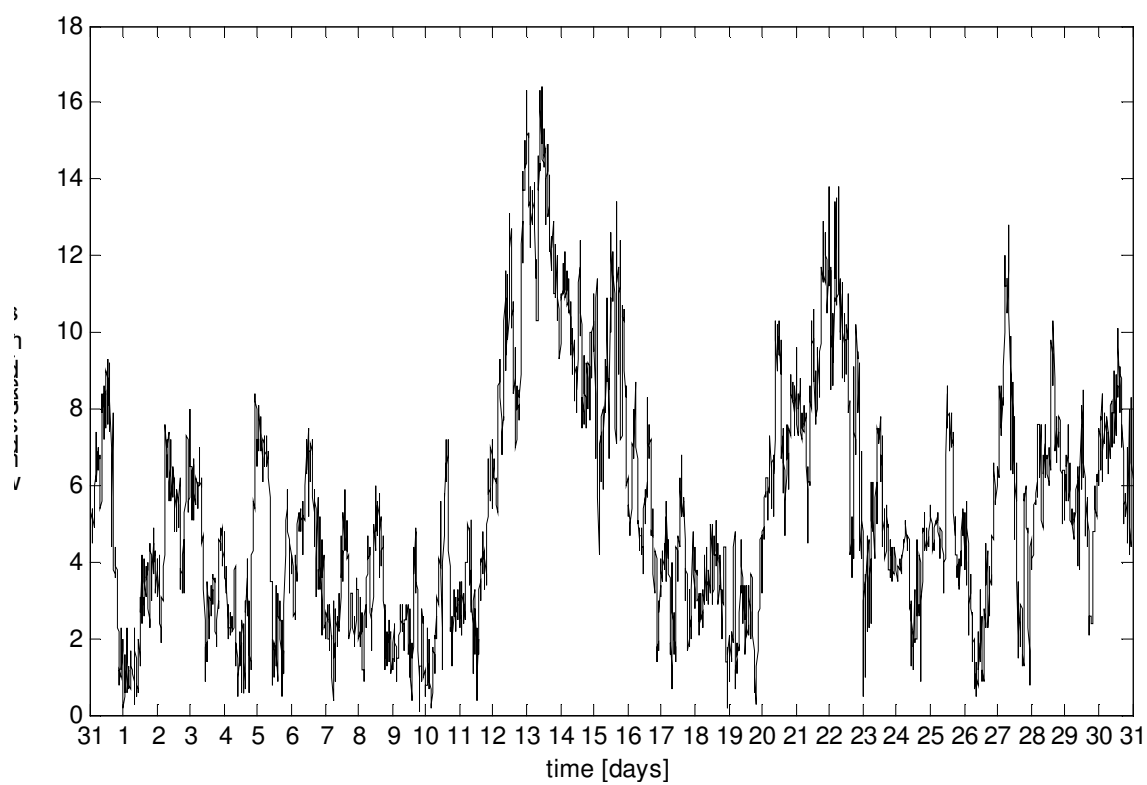

Fig. 3. Typical monthly wind speed raw data 
A particular (and very common) case of Weibull PDF is the case where $k=2$. It is called Rayleigh $\mathrm{PDF}$ and is given by

$$
f_{R L H}(v)=\frac{2 v}{c^{2}} e^{-\left(v / c^{2}\right.}
$$

for positive wind speeds $(v>0)$ with scale parameter $c$ related to the site mean wind speed as

$$
\mu_{v}=\frac{\sqrt{\pi}}{2} c
$$

making (6) to be dependent on average wind speed as

$$
f_{R L H}(v)=\frac{\pi v}{2 \mu_{v}^{2}} e^{-\left(\sqrt{\pi} v / 2 \mu_{v}\right)^{2}}
$$

It is worth noting that wind energy resource is typically classified according to average wind speed at $10 \mathrm{~m}$ height as shown in Table 1[11].

Table 1

Wind power classification

\begin{tabular}{|c|c|}
\hline $\begin{array}{c}\text { Wind Power } \\
\text { Class }\end{array}$ & $\begin{array}{c}\text { Average Wind Speed }\left(\mathbf{m}^{-\mathbf{1}} \mathbf{)}\right. \\
\text { at 10 } \mathbf{~ m} \text { Height }\end{array}$ \\
\hline 1 & $0-4.4$ \\
\hline 2 & $4.4-5.1$ \\
\hline 3 & $5.1-5.6$ \\
\hline 4 & $5.6-6.0$ \\
\hline 5 & $6.0-6.4$ \\
\hline 6 & $6.4-7.0$ \\
\hline 7 & $>9.5$ \\
\hline
\end{tabular}

Since power in the wind increases with height $[12 ; 13]$, the turbine hub of medium and large scale wind turbines is usually located a $50-150 \mathrm{~m}$ height. Therefore statistical wind parameters must be either measured at hub height or extrapolated from measurements available at smaller heights. In case single height measurements only are available, power law is usually employed to estimate wind speed $v_{l}$ at height $H_{1}$ as

$$
\left(\frac{v_{1}}{v_{0}}\right)=\left(\frac{H_{1}}{H_{0}}\right)^{\alpha}
$$

where $v_{0}$ is the wind speed measurement available at height $H_{0}$ and $\alpha$ is the surface roughness dependent friction coefficient $[14 ; 15]$. Friction coefficient dependence on terrain characteristics are typically determined from Table 2 [11].

Table 2

\section{Friction coefficient dependence in terrain type}

\begin{tabular}{|c|c|}
\hline Terrain Characteristics & $\boldsymbol{\alpha}$ \\
\hline Smooth hard ground, calm water & 0.10 \\
\hline Tall grass on level ground & 0.15 \\
\hline High crops, hedges and shrubs & 0.20 \\
\hline Wooded countryside, many trees & 0.25 \\
\hline Small town with trees and shrubs & 0.30 \\
\hline Large city with tall building & 0.40 \\
\hline
\end{tabular}

According to the above, a MATLAB simulator was created receiving meteorological data (excel format) as an input and calculating the following output. Using the wind speed raw data, mean and standard deviation (STD) values were calculated, followed by Weibull parameters extraction and 
plotting respective histograms along with resulting Weibull PDFs. All the results were calculated monthly, yearly and seasonally. Annual Rose diagrams were created as well.

\section{Results and discussion}

Table 3 summarizes cumulative mean and STD of wind speed and azimuth. It may be concluded that the wind belongs to class 2 , according to Table 1 .

\section{Cumulative wind speed statistics}

\begin{tabular}{|c|c|c|c|}
\hline Year & Parameter & Speed & Azimuth \\
\hline \multirow{2}{*}{$2001-2011$} & Mean & 4.53 & 226.00 \\
\cline { 2 - 4 } & STD & 2.32 & 79.76 \\
\hline
\end{tabular}

Table 3

Table 4 summarizes monthly, yearly and cumulative Weibull parameters of wind speed. It may be concluded that winds in Ariel may be accurately assumed as Rayleigh since the cumulative $k$ is very close to 2 .

Cumulative Weibull parameters at $10 \mathrm{~m}$ height

\begin{tabular}{|c|c|c|}
\hline Year & Parameter & Value \\
\hline \multirow{2}{*}{$2001-2011$} & $k$ & 2.05 \\
\cline { 2 - 3 } & $c$ & 5.12 \\
\hline
\end{tabular}

Table 4

In order to validate the applicability of Weibull PDF to wind statistics in Ariel, Fig. 4 presents cumulative wind speed raw data histogram and Weilbul PDF. Good matching is evident.

Another important aspect of wind analysis is prevailing wind direction (azimuth). Eleven years Cumulative wind rose diagram is shown in Fig. 5.



Fig. 4. Wind speed raw data Histogram and Weilbul PDF

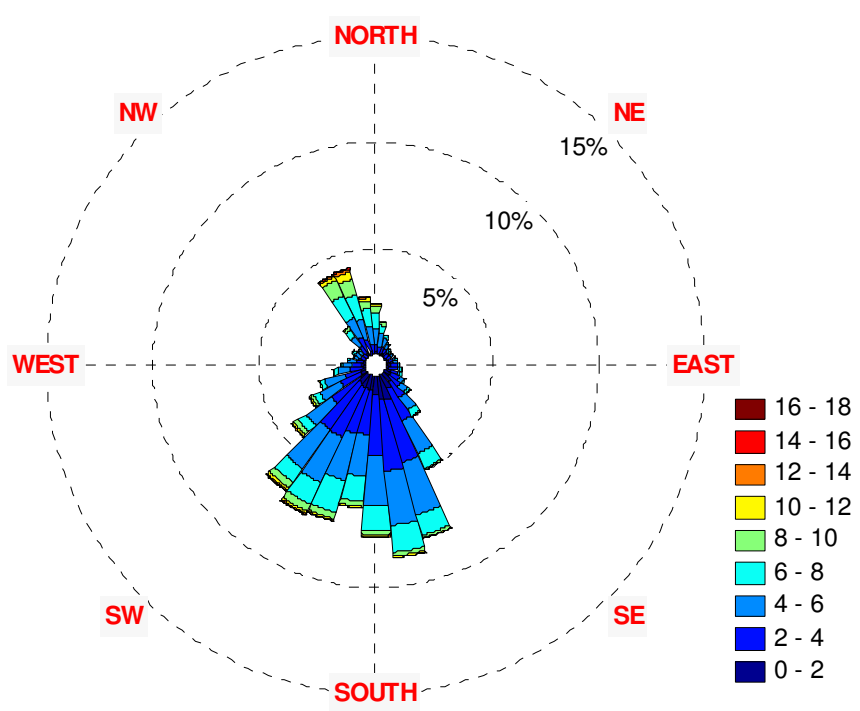

Fig. 5. Wind rose diagram 


\section{Conclusions}

In this work, statistical characteristics and Weibull parameters of the wind speed in Samaria region have been extracted from 11 years of wind data provided by the Israeli Meteorological Service, acquired at $10 \mathrm{~m}$ height above the ground. The cumulative mean wind speed at measurement height was found to be $4.53 \mathrm{~m} \cdot \mathrm{s}^{-1}$ with standard deviation of $2.32 \mathrm{~m} \cdot \mathrm{s}^{-1}$. Prevailing wind direction is shown to be characterized by cumulative mean azimuth of $226^{\circ}$ with standard deviation of $79.76^{\circ}$. Weibull distribution parameters were calculated, demonstrating good match with histogram-based statistical representations. Shape parameter of Weibull distribution was shown to reside within narrow range around 2, allowing to assume Rayleigh statistics.

\section{References}

1. Himri Y., Rehman S., Draoui B., Himri S.. Wind power potential assessment for three locations in Algeria. Renewable and Sustainable Energy Reviews, vol. 12, 2008, pp. 2495-2504.

2. Ackera T. L., Williams S. K., Duquea E., Brummels G., Buechler J. Wind resource assessment in the state of Arizona: Inventory, capacity factor, and cost. Renewable Energy, vol. 32, 2007, pp. 1453-1466.

3. "GWEC, Global Wind Report Annual Market Update". Gwec.net. [online][14.05.2011] Available at: http://www.gwec.net/index.php?id=180.

4. "EWEA - European Wind Energy Association", [online][14.05.2011] Available at: http://www.ewea.org/index.php?id=1487.

5. Israel Ministry of Environmental Protection, "Renewable Energy", [online][31.07.2014] Available at: http://www.sviva.gov.il.

6. "Wind energy power generation", Background paper written by Orli Lotan, 21.09.05. Knesset, Research and Information Center, Jerusalem, 2005, p. 3 (in Hebrew).

7. Ditkovich Y., Kuperman A., Yahalom A., Byalsky M.A generalized approach to estimating capacity factor of fixed speed wind turbines. IEEE Transactions on Sustainable Energy, vol. 3, 2013, pp. 607-608.

8. Ditkovich Y., Kuperman A., Yahalom A., Byalsky M. Site-dependent wind turbine performance index. International Journal of Renewable Energy Research, vol. 3, 2013, pp. 592-594.

9. Ditkovich Y., Kuperman A. Comparison of three methods for wind turbine capacity factor estimation. The Scientific World Journal, vol. 805238, 2014, pp. 1-7.

10. Chang T. Performance comparison of six numerical methods in estimating Weibull parameters for wind energy application. Applied Energy, vol. 88, 2011, pp. 272-282.

11. Masters G. Renewable and efficient electric power systems. John Wiley \& Sons, New York, 2004.

12. Kuperman A., Rabinovici R., Weiss G. Torque and power limitations of a shunt connected inverter based WECS. WSEAS Transactions on Circuits and Systems, vol. 7, 2005, pp. 684-690.

13. Kuperman A., Rabinovici R., Weiss G.A shunt connected inverter based variable speed wind turbine generation. International Journal of Electromotion, vol. 13, 2006, pp. 67-72.

14. Gualtieri G., Secci S. Extrapolating wind speed series vs. Weibull distribution to assess wind resource to the turbine hub height: A case study on coastal location in Southern Italy. Renewable Energy, vol. 62, 2014, pp. 164-176.

15. Gualtieri G., Secci S. Methods to extrapolate wind resource to the turbine hub height based on power law: A 1-h wind speed vs. Weibull distribution extrapolation comparison. Renewable Energy, vol. 43, 2013, pp. 183-200. 